\title{
Teambuilding, Innovation And The Engineering Communication Interface
}

\author{
David Prescott, American University of Sharjah, United Arab Emirates \\ Tharwat El-Sakran, American University of Sharjah, United Arab Emirates \\ Lutfi Albasha, American University of Sharjah, United Arab Emirates \\ Fadi Aloul, American University of Sharjah, United Arab Emirates \\ Yousef Al-Assaf, American University of Sharjah, United Arab Emirates
}

\begin{abstract}
Recent engineering industry-based research has identified a number of skill deficiencies in graduating engineers. Emphasis on communication and teamwork informed by attributes of self management, problem solving and mutual accountability have been recognized as important needs by The Engineering Accreditation Commission of ABET of the United States and are now required in undergraduate course material. The Engineering College at the American University of Sharjah has recognised this reality with the development of a course in language enhancement and professional communication centred on engineering multidisciplinary projects (EMDPs). This paper will outline four innovative practices that together inform this course; team-building, teamwork management, collaborative problem solving, resource management. Brief illustrative descriptions of: team-building through the use of the Belbin Team Role Inventory; management of teamwork development via planning and documentation; personnel and collaborative problem solving and interactive information sources hosted via a LibGuide will elaborate these innovative practices.
\end{abstract}

Keywords: Team; Communication; Behaviour; Teamwork; Collaborative

\section{SKILL DEFICIENCIES OF ENGINEERING GRADUATES}<smiles>CC1CCCCC1</smiles>
$\mathrm{n}$ this section of the paper we deal briefly with two issues. These are: what evidence is there to support the claim of skill deficiencies in graduating engineers and what are these skill deficiencies?

Industry based and academic research during the last decade has emphasized the need for engineers to be able to integrate technical expertise with behavioral and societal issues, to work on solving complex problems in teams composed of professionals from many disciplines and to exhibit high level communication skills. These concepts are derived from the OECD's 'Definition and selection of competencies: theoretical and conceptual foundations' (DeSoCo) project, which is foundational to many of these studies. The project work, published under the editorship of Rychen and Salganik (2003), developed a conceptual frame of reference for key competencies. It was based on theoretical and conceptual approaches to competence informed by political and practical considerations. The rationale for the work took into account three key factors. These are the fact that rapid and continuous change in technology would require adaptability rather than mastery; that social diversity would necessitate different kinds of personal relationships (more contact with those different from oneself); that globalisation would create interdependencies with actions subject to influences and consequences beyond regional and national boundaries (economics and pollution for instance).

Investigations based on the DeSoCo conceptual frame of reference, such as that conducted in Malaysia by Zaharim et al (2008), have recognized that changes in economic growth patterns are creating higher demands for engineering employability skills. The Zaharim study identified deficiencies between the perceptions and the 
expectations of employers and showed that significant gaps exist between the skills actually possessed by employees and those considered important by employers. Significant deficiencies were found in teamwork, communication and problem-solving with associated weaknesses in understanding professional, social and ethical responsibilities. An earlier qualitative study conducted by Martin et al (2005) with chemical engineering graduates in South Africa revealed similar findings. The study showed that the foundations of academic success for the respondents, technical knowledge and technical skills, were not sufficient for success in the profession. Attributes related to industry (interpersonal skills, communication, teamwork and management) needed to build on the academic/technical foundation. In particular, this study emphasized that communication is dependent on interpersonal skills, and that teamwork and management are dependent on communication.

In a mid-decade study of the Indian engineering education sector, Goel (2006) found that traditional resource-based approaches were still very much in evidence rather than the outcome-based approaches which would address the perceived lack of requisite competencies such as "ability to apply knowledge, design skills, problem solving skills, ... ability to work in multidisciplinary teams, communication skills, sensitivity towards global, societal, and environmental issues, and sensitivity towards ethical and professional issues" (p. 48). Goel's proposal to alleviate this lack was the adoption of a three-dimensional framework of competencies to categorize the skills that address existing deficiencies and emerging needs. The framework included firstly, attitudes and perceptions then productive habits of mind and finally acquisition and meaningful use of knowledge.

Male, Bush and Chapman reporting on recent work in this field show the competency requirements of the engineering industry in Australia reflect those identified in international studies. In recently published work (2010a), conducted with 300 Australian engineers with between 5 and 20 years experience, the findings highlight competency deficiencies in engineering business, communication skills, self management and attitude, problem solving and teamwork. Practising engineering professionals identified these deficits in recently graduated colleagues. In related work the same researchers describe the adaptation of the DeSoCo conceptual framework for understanding competencies to generic engineering competencies and confirmed the inclusion of attitudinal elements (Male, Bush \& Chapman, 2010b). Earlier studies are in accord with these findings. For instance, Spinks, Silburn and Birchall showed the skills sets required by engineering firms to include social and interpersonal skills and attributes including communication skills, team-working skills, and business skills $(2006,3)$. Other studies have highlighted such competencies as in need of improvement. Bodmer et al (2002), in a European and US survey of 1372 engineers, identified leadership, social skills and communication to be lacking in graduates; an international survey (WCEC, 2004) of 2,158 young chemical engineers from 63 different countries during their first five years of employment found deficits in management, effective communication and leadership. Male, Bush \& Chapman assert "communication is the competency that features most frequently as a deficiency in Australian surveys" (2010, 56) and work conducted by Ashman et al (2008) and Nair et al (2009) concurs.

The evidence is clear. Perusich et al (2007, TSE-2) writing about the issues to be addressed for accreditation by the Engineering Accreditation Commission of ABET of the United States have observed "Most engineering and technology graduates will work in business on projects that have significant complexity and require multiple skill sets". In summary then engineering graduates require sound technical knowledge but also excellent written and oral communication skills plus team working, management and problem solving skills.

\section{ADDRESSING SKILL DEFICIENCIES AT THE AMERICAN UNIVERSITY OF SHARJAH}

Engineering undergraduates at the American University of Sharjah (AUS) were no exception to this widely perceived need to address skill deficiencies in communication, team working, management and problem solving. Prior to the Spring Semester 2010 the College of Engineering (CEN), acting upon some recommendations made by ABET (see Appendix 1), designated a technical writing course, ENG207: English for Engineering a prerequisite study for engineering students. Furthermore the Dean of CEN requested the Department of English to incorporate a multi-disciplinary project into this course in order to provide the engineering undergraduates training in a range of collaborative, communication, team working and problem-solving skills. A pilot program was developed and implemented during the Spring Semester, 2010 with three of the ten sections in the course. These sections were taught by the first two authors of this paper. Liaison with two faculty from the CEN (nominated by the Dean, CEN) occurred on a regular basis. 
The syllabus revision was also made in response to employers' and students' complaints that AUS engineering trainees and graduates lacked the skills needed for communication with co-workers, supervisors and employers. As a consequence, it is now (Academic year 2011-2012) policy that AUS engineering students study ENG207 during their third academic (Junior) year before conducting their senior design projects and prior to internship. ABET also made a firm recommendation that engineering students from different majors should participate in multidisciplinary engineering projects that require individual input from each of the students in the team. Since this proved difficult to implement in specialized engineering courses, where students from different majors study separately from others, the most suitable context was clearly ENG207 which comprises students from all engineering disciplines and from different cultural and ethnic backgrounds. Thus an engineering multidisciplinary project (EMDP) component has been incorporated into ENG207 in order to provide engineering undergraduates training in a range of collaborative, communication and academic skills typically found in engineering workplaces. Since the course contents cover, in addition to research skills, other vital communication and academic skills, the writers have incorporated the skill sets in the body of the engineering multidisciplinary project. EMDP-based teaching and learning provides an appropriate context for introducing, developing and implementing both research and professional communication skills.

In terms of methodological requirements these changes have demanded of faculty a strong focus on student-centred learning and a substantial reduction in traditional, teacher-fronted modes of delivery and learning. The innovations that are described in the next section of the paper are indicative of this shift in methodology. Regular meetings with faculty in which the emphasis has been on sharing "good practice" and encouraging reflection on the demands of the revised syllabus continue to help shape development of an appropriate, proactive methodology amongst colleagues teaching the new program.

\section{INNOVATIVE PRACTICES AT THE AMERICAN UNIVERSITY OF SHARJAH}

In this section of the paper we examine four innovative practices adopted to address these skill deficiencies. These practices resulted from syllabus change management informed by cross discipline planning and course development which have transformed a technical writing course, into a language and communication training course for undergraduate engineers in profession-oriented collaborative, communication and academic skills. The change was driven by three factors; ABET recommendations, academic and professional research, employer and alumni feedback. In response, an engineering multidisciplinary project (EMDP) component has been incorporated into the revised course to provide engineering undergraduates training in a range of collaborative communication and academic skills typically found in engineering workplaces. In fact it is now policy that engineering students must study this course during their third (junior) academic year before conducting their senior design projects and prior to internship. Since the course contents cover in addition to research skills other vital communication and academic skills, the skill sets have been incorporated in the body of the engineering multidisciplinary project. EMDP-based teaching and learning provides an appropriate context for introducing, developing and implementing both research and professional communication skills; shown in Figure 1.

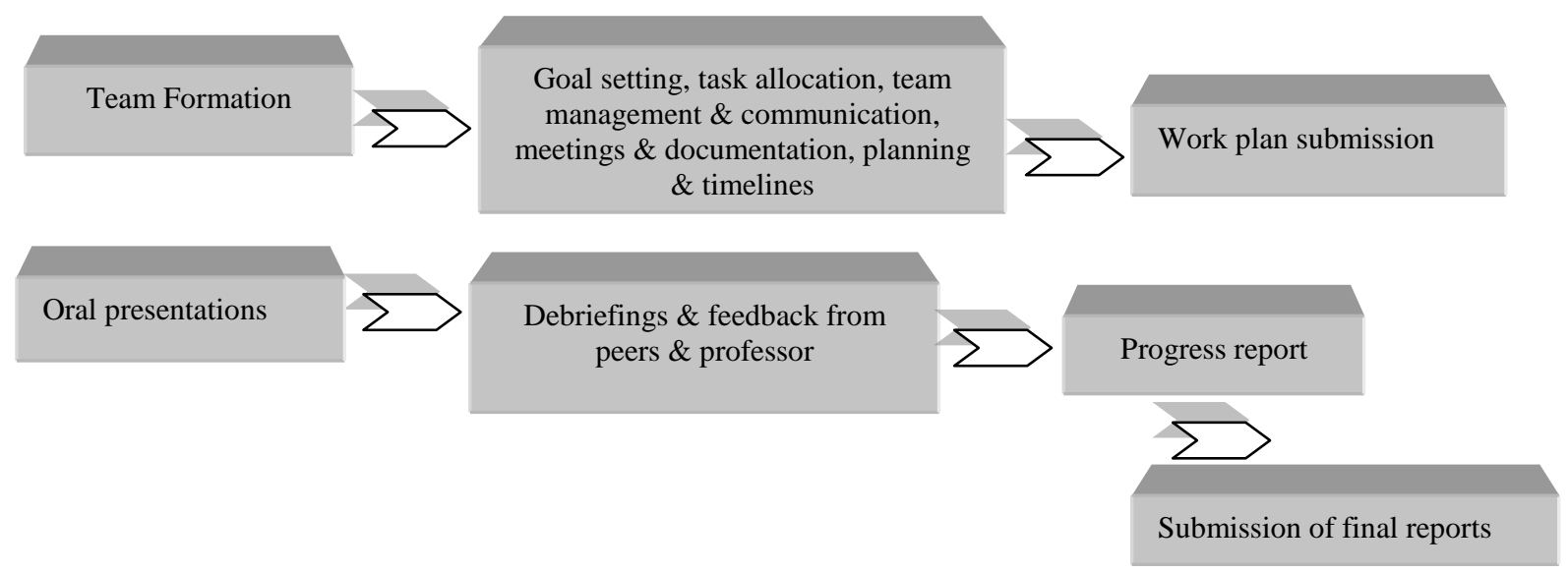

Figure 1: EMDP - Development and Implementation Model 
The EMDP "package" can be viewed as a pedagogical tool and as having considerable agency in promoting attainment of students' professional communication skills. Emphasis is on team-role behavior place with resulting prominence given to personal, inter-personal and team learning. Students engage in team-building informed by the use of the Belbin ${ }^{\circledR}$ Team Role Inventory and engage in management of teamwork development via Gantt chart time-based planning and meeting documentation. Furthermore, they employ interactive information sources hosted via a LibGuide to resource personal and collaborative team problem solving. It is these practices that are now explained.

\section{TEAM BUILDING}

Belbin ${ }^{\circledR}$ Team Role Theory is based on work conducted by Dr Meredith Belbin and his research team at Henley Management College (University of Reading) beginning in the 1970s. The research revealed that difference between success and failure for a team was primarily dependent on behavior. Separate clusters of behavior, each of which formed distinct team contributions or "Team Roles" were identified and it was further discovered that different individuals displayed different team roles to varying degrees. The key to a successful team is to achieve balance across these various team roles. For instance the research team found that a team with no "plant" struggled to initiate ideas but that too many plants resulted in a confusion of ideas. The absence of a "shaper" meant the team "mooched" along lacking drive and direction. The nine team work behaviors identified by Belbin® and his researchers are clearly shown in Figure 2.

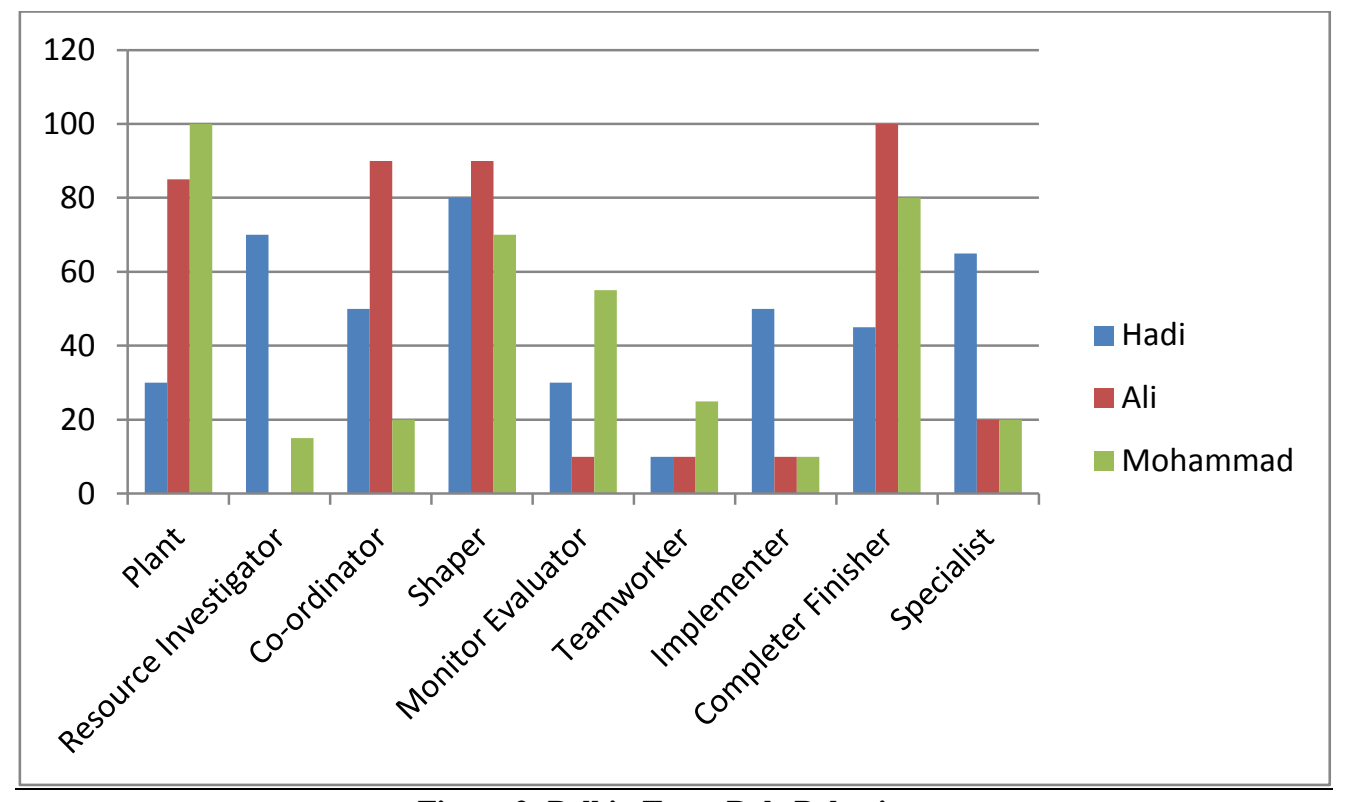

Figure 2: Belbin Team Role Behaviors

In the case of our students, who are required to work in engineering multidisciplinary teams with people they don't know, the Belbin ${ }^{\circledR}$ material is used to help build team cohesion. Our engineering juniors complete a Belbin ${ }^{\circledR}$ Self-Perception Inventory (SPI). This is a questionnaire that takes about 20 minutes to complete and provides the students with a report that identifies their preferred, manageable and least preferred roles. Display of these preferences in the format illustrated in Table 2 allows a team to readily identify their strengths and shortcomings and to build team capacity accordingly. Students complete the SPI at the commencement of the semester and then again at the close. Shifts in preferences indicate changes to their understanding of the relationships between the behaviors they exhibit and the effects of these behaviors on the members of their team. Teams that are able to achieve a balanced distribution across the nine behaviors generally function more productively than those that do not. It is our contention that understanding of these behaviors and knowledge of personal and team preferences aids team-building significantly. For instance, many teams refer to the Belbin ${ }^{\circledR}$ 
behaviors in their oral and written EMDP reports and are able to attribute early difficulties with topic identification and productive teamwork to imbalances in their team members' preferences. The following reflective observation shows this understanding:

Working with three compatriots with different backgrounds, disciplines and personalities gave rise to many potential disagreements and conflicts in opinion. During our weekly meetings when ideas and suggestions were brought to the table, I had to make sure that my personal expectations and requirements did not obstruct the progress of the team. Being an admitted perfectionist with a tremendous regard for detail and specificity I often had to voice these concerns as pertaining to our project at hand. To maintain respect I phrased the majority of my concerns diplomatically in backhanded technical-based questions which could only be construed as technical related queries as opposed to challenges. (Aishwarya Menon)

It was not by chance that this student showed strong preference for completer/finisher and specialist team role behaviors in both SPI administrations but in recognition of the need to build team cohesion recorded a noticeable preference increase in teamwork at the end of the semester.

\section{PERSONNEL AND COLLABORATIVE PROBLEM SOLVING}

The Belbin ${ }^{\circledR}$ resources are helpful and valued by students and faculty, but they do not help students deal with the problem behaviors that the EMDP teams encounter. As a population our engineering juniors include individuals who exhibit the full range of difficult, obstructive conduct which is counter-productive to effective teamwork. The reality is that such conduct exists in all workplaces and we address the issue by identifying helpful strategies to modify behavior. For this we use the Video Arts Managing Problem People Series. In this series six problem types are featured; Bigmouth Billy, Rulebound Reggie, Lazy Linda, Wimpy Wendy, Silent Sam and Moaning Minnie. Twelve to nineteen minute scenarios are enacted with the outcomes being to develop understanding of how to maximise individual potential and effect positive change. A common factor that runs through all the programs is that change is two-pronged; change of leadership behavior can cause a positive change in individual behavior.

Students work in their teams for this exercise. Each team views one of the programs, they identify the underlying problem and the solution enacted in the video program. They extrapolate the problem and solution to their EMDP teams and offer possible advice on courses of action that could be used to modify behavior and build team cohesion. After reporting to the class a template of behavior characteristics and possible tactics for modification is prepared. This collaboration results in a resource for all teams to draw on. A sample of the segment for Big Mouth Billy is shown in Figure 3.

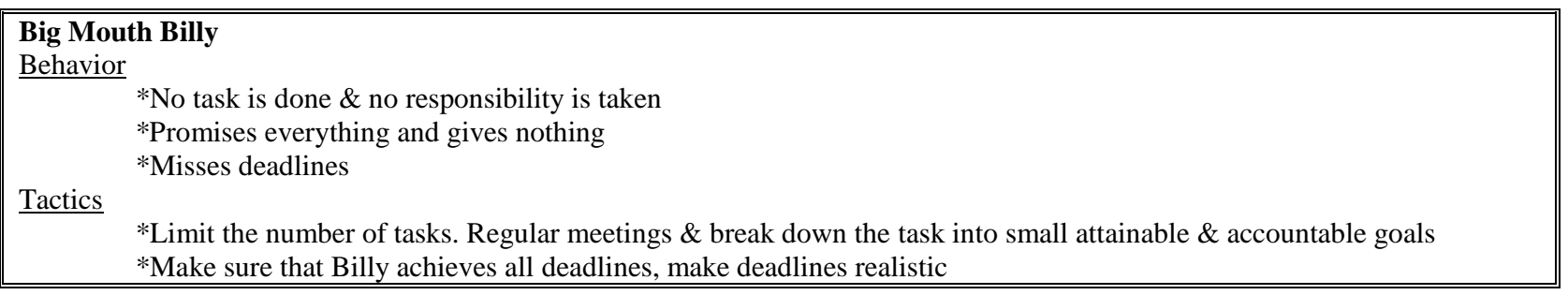

Figure 3: Managing Problem People: behavior recognition and modification reflection.

Evidence that students draw on these segments of advice is indicated in the following example of student

However, this is when we encountered another challenge which was making sure each of the team members followed the plan. This was especially difficult because I realized that we had a "Bigmouth Billy" character in our team. The team member promised to do a number of tasks never met deadlines or attended follow-up meetings. We managed to tackle this by resorting to the Problem People advice sheet; we set more achievable deadlines, documented each team member's tasks and sent out an email which included all the details following each meeting. This did not completely overcome the problem but was greatly helpful. (Shamma Salah Alqassim) 
The exercise was collaborative at class and team level. It provided resources that enabled individuals to recognise issues that needed resolving, it offered a range of possible tactics for dealing with the problem and the template resulted from cooperative endeavour.

\section{PLANNING AND DOCUMENTATION}

In the abstract this innovation is described as "management of teamwork development via planning and documentation". The need for engineering juniors to plan and to document their planning and their decision making is an ABET requirement and an industry necessity. It is our belief that the teaching and learning of requisite professional communication skills, in particular calling for meetings; preparing meeting agendas; minuting meeting procedures; documenting teamwork decisions; distributing work tasks and setting timelines should be contextualized $(\mathrm{Yu}, 2008)$. In our course the teaching of these skills within the engineering multidisciplinary project demonstrates their appropriate uses in various authentic communication situations (Amare and Brammer 2005). In keeping with Chun's (2010) ideas documentation of meetings and informal decision making is collated in a portfolio and assessed for efficiency, accuracy and overall quality in three categories: formal meeting documents, informal decisions and planning. Engineering juniors have heavy schedules and so planning is a significant skill they need to develop in order to maximize efficient use of time. We encourage Gantt chart time-based planning as the important variables of time (start, finish, duration), tasks, personnel, deadlines are incorporated in the planning software. The example at Figure 4 is for an eight day resource investigation.

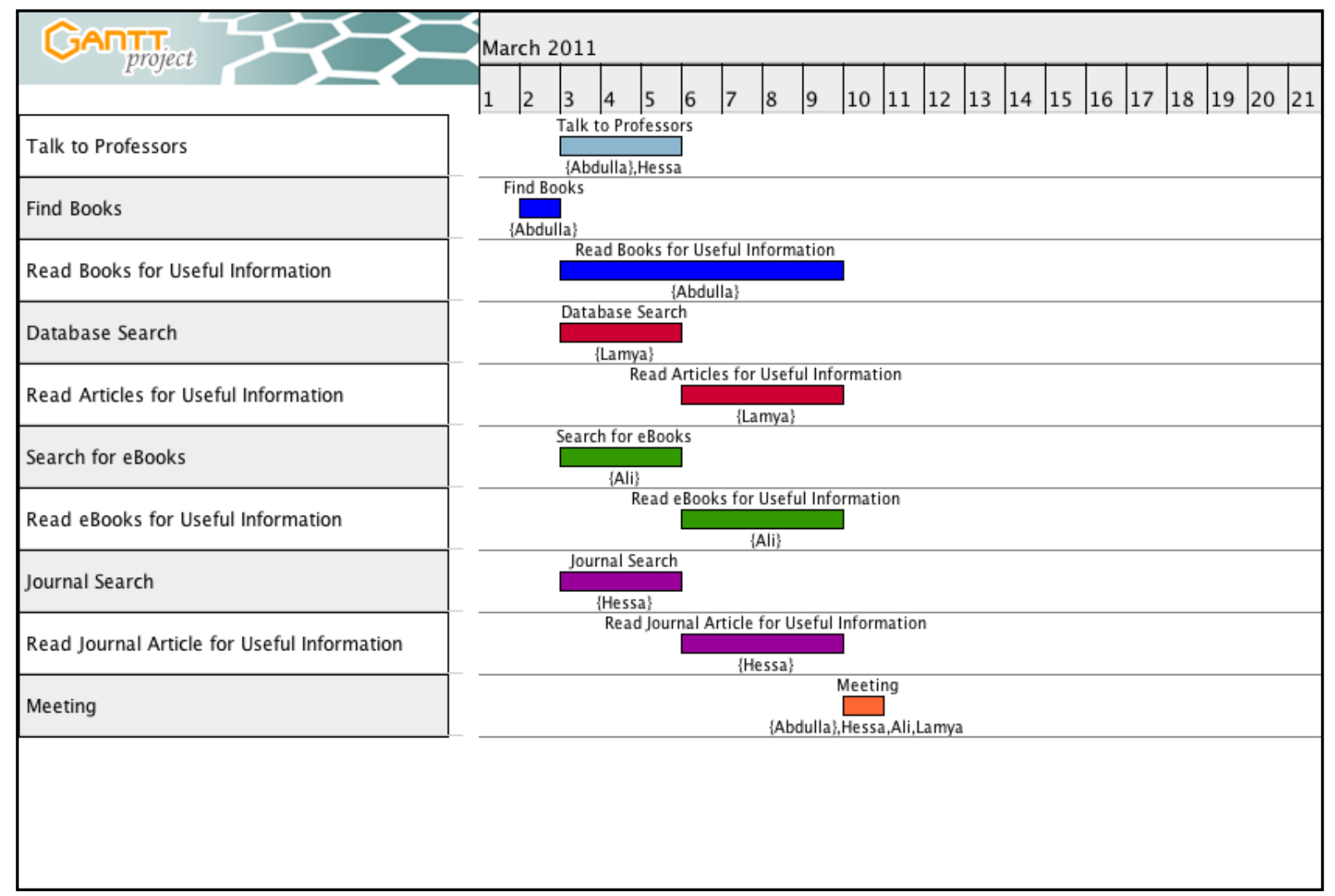

Figure 4: Time-based planning example

Planning and documentation transfers responsibility for monitoring learning to students and recalls work by Paris and Winograd (1990) which showed that this kind of accountability enhances students' development of problem-solving strategies, improves their learning because of an increased awareness of thinking and improves motivation. Improved levels of motivation and positive self-perception may also result and the social exchange environment of effective teamwork reveals aspects of Vygotsky's (1978) theory of socially mediated learning. The 
learner-centred approach, where students are actively engaged in the discovery and construction of their own knowledge and meaning through attempting solutions to real problems from their surrounding environment (Appendix) reflects Choo (2007) who aptly states "There is an increasing need to train students to solve real-world problems so that they can handle complex problems in their workplace" (p.187).

\section{LIBGUIDE}

Our revised course is resourced through the American University of Sharjah Library LibGuide service. In keeping with the collaborative, learner-centered nature of the course the use of a Libguide makes a great deal of sense. First there is the capacity to gather all materials that inform the course together for easy, efficient and stable access. This includes books (print and e-books) under Reference Shelf; engineering and science journals available through the Journal Finder function under Core Journals; access to Key Databases significant for engineering juniors (Science Direct, IEEE Explore, Academic Research Library, Access Science); Recommended Websites which allow us to draw on resources outside our library; Multimedia Resources which provides links to training material we wish the students to access and finally Student Work where we post exemplar materials. Colleagues value the LibGuide for its capacity to host diverse resources, its flexibility, the fact that currency of materials is no longer an issue (as it can be with course books) and the value that we derive from showcasing high quality student work. The power of local examples of work in comparison to the remote example in a textbook cannot be underestimated. Students are able to provide comments on resources they find helpful or not and they can post their own materials.

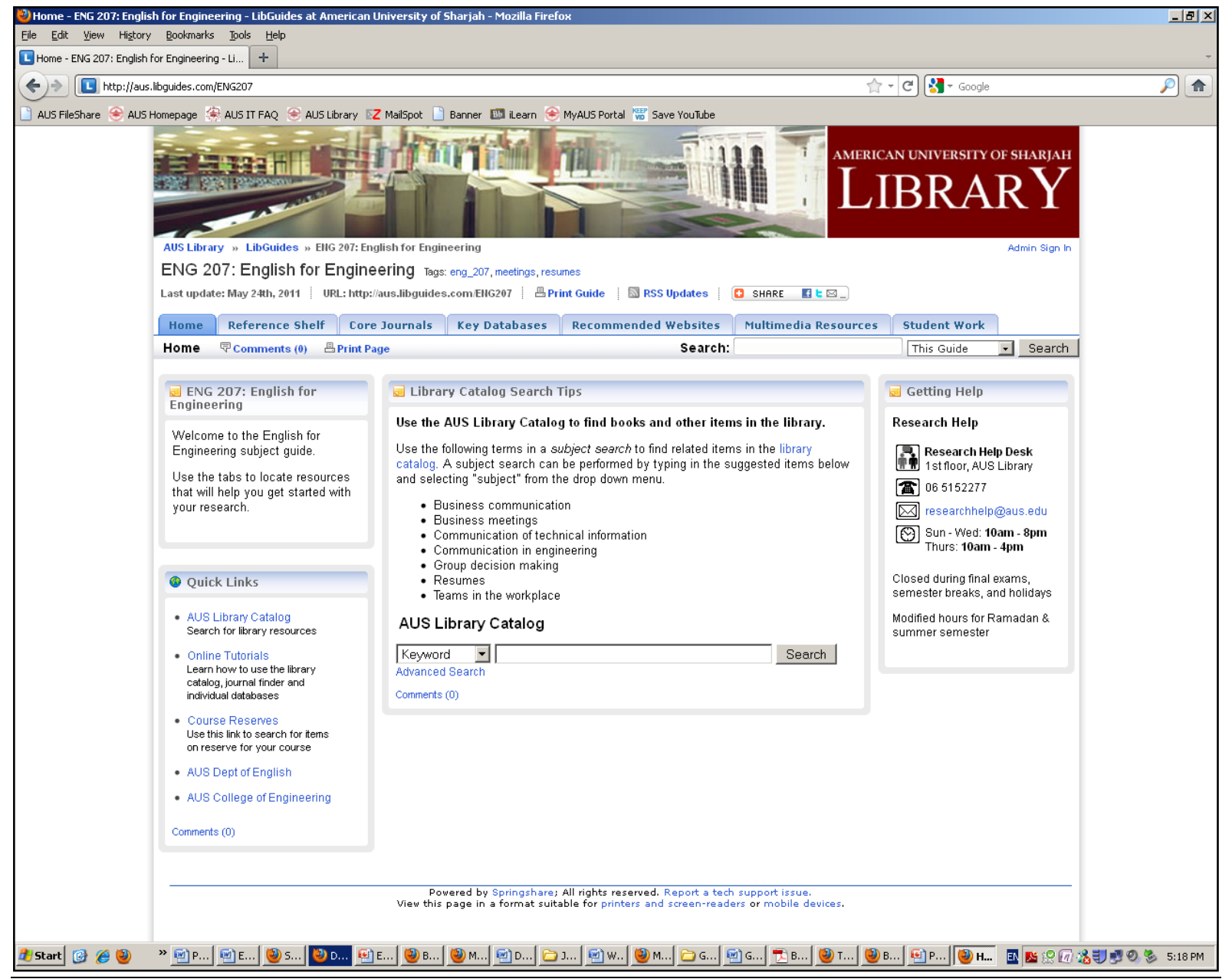

Figure 5: LibGuide Home Page 
The LibGuide is a resource that supports situated motivation and clearly places responsibility for learning on students. We have noticed that those students who respond early to this challenge progress well and engage the coursework effectively while those who struggle to adapt only begin to realize the benefits of the approach once they throw off the shackles of the deficit model (Wilhelm et al, 2001) and its inherent passivity. Figure 5 shows the Home Page for the Libguide that resources this course.

\section{RESULTS AND FUTURE DIRECTIONS}

It is accurate to characterize the changes in ENG 207 as embracing features of situated cognition or situated learning as explained by Brown, Collins and Duguid (1989). The critical factors of apprenticeship, collaboration, reflection, coaching, multiple practice and articulation (McLellan, 1991, 1994) strongly reflect components of the engineering multidisciplinary project (EMDP). McLellan's point, that while knowledge must be learned in context, "a highly realistic or 'virtual' surrogate of the actual work environment" (Herrington and Oliver, 1991) may serve to develop knowledge and skills, is pertinent to the work and the innovative practices described here. Brown, Collins and Duguid's model of cognitive apprenticeships, is a method designed to 'enculturate students into authentic practices through activity and social interaction', and is based on the successful and traditional apprenticeship model (1989, p. 37). This is in part what occurs in the EMDP and in keeping with practices in other disciplines (business studies and architecture) input from practicing professionals has recently been utilized to underscore the significance of a meaningful learning context. In the Spring semester, 2011 Christian Nielsen, Fire Engineering Manager at AECOM Technology Corporation (Middle East) lectured the ENG 207 cohort of 250 students on the significance of professional communication skills for practicing engineers. Interaction of this kind, between the academy and the workplace, reinforces the purposeful, situated learning model that the EMDP approach (Figure 1) exemplifies.

Initial evidence for the success of these innovations is based on the students' achievement as exhibited in overall grades. Overall grade results expressed as percentage for classes involved in the trial of the revised ENG207 syllabus (Spring Semester 2009, Fall Semester 2010) averaged 84.77 with a median of 84.84. Classes studying under the former syllabus (Fall Semester 2009) averaged 83.93 with a median of 84.37. The gains may appear modest but it should be remembered that the revised syllabus requires students to undertake a far greater variety of tasks, there is a greater quantity of work and the cognitive demands are more consistently higher order. There is also a significant increase in personal responsibility mandated in the revised syllabus. Given these factors and the outcome of the statistical analyses, the results are encouraging.

Currently a study (Prescott, El-Sakran and Mesanovic) is being conducted to determine the effect of the EMDP approach on results engineering seniors achieve in their senior design projects. The revised ENG 207 course is considered a more apposite preparation for the final year of the undergraduate degree program. Results from the study, which will compare levels of student achievement prior to the ENG 207 revision with post revision results, will reveal if there is any measurable improvement.

\section{CONCLUSION}

In this paper we have reviewed the research that shows that graduating engineers have a number of skill deficiencies. This work reviewed commenced over a decade ago and has continued to the present. Then we discussed changes at the American University of Sharjah, made to address these skill deficiencies in the undergraduate engineering students at junior year level. The changes have been incorporated into a course which has become mandatory for engineering junior students. We then discussed four innovative practices (team-building, planning \& documentation, collaborative problem solving and resource management) which have focussed students on situated motivation.

We cannot pretend that all is proceeding without difficulties and teething problems. No innovation can be implemented without unforeseen problems emerging. However such problems may seen as growth points that should be challenged and overcome. For instance, uneven team role behavior and inability to adapt to the proactivity required by the practices described in this paper are the greatest challenges faced by students. In acceptable cases teams and individual members struggle to adapt but eventually through some defining moment of experience and with faculty guidance and input they embrace the responsibility and begin to mature. In poor cases team 
disfunctionality is never successfully overcome and individuals remain incapable of change maturation. In some cases an individual's progress and achievement is negatively affected by the deficit behaviors of the majority. These are issues that are currently receiving attention.

\section{AUTHOR INFORMATION}

David Prescott: At the American University of Sharjah (AUS) I coordinate the Professional Communication course all engineering undergraduates study in their junior year. I supervise and examine MA TESOL students' theses and I teach Leadership and Management and Technology in the Classroom in the MA program as well as courses concerned with teaching and learning with ICT at undergraduate level. I manage a cross-discipline research team investigating faculty and academic staff use of the AUS Course Management System (CMS), iLearn. I am a member of a cross-disciplinary research team investigating the extent to which the Professional Communication course for engineering juniors impacts on their senior design project results. E-mail: dprescott@aus.edu. Corresponding author.

Tharwat El-Sakran is a Professor of Linguistics in the English Department at the American University of Sharjah in the United Arab Emirates. His research interests are in the fields of teaching English as a foreign language, English for specific purposes, discourse analysis, translation and socio-linguistics. E-mail: telsakran@aus.edu.

Lutfi Albasha is Assistant Professor of Electrical Engineering at the American University of Sharjah. He has been awarded a number of research grants including a United Arab Emirates Defense Army Research Grant in 2010 and Emirates Foundation Research Grants in 2009 and 2008.

Fadi Aloul is Associate Professor of Computer Engineering at the American University of Sharjah. His research interests include Optimization, Design Automation and Computer Security. He was awarded the HH Sheikh Khalifa Award for Higher Education in 2008-2009.

Yousef Al-Assaf is Professor and Dean of the College of Engineering (CEN) at the American University of Sharjah (AUS). His on continuous assessment of the CEN programs secured their national and international accreditations, including ABET accreditation. The CEN at AUS was the first engineering college in the Middle East region and the second outside the US to gain ABET accreditation.

\section{REFERENCES}

1. Amare, N. \& Brammer, C. (2005). Perceptions of memo quality: A case study of engineering practitioners, professors, and students. Journal of Technical Writing and Communication, 35(2), 179-190.

2. Ashman, P. J., Scrutton, S., Stringer, D., Mullinger, P. J. \& Willison, J. (2008). Stakeholder Perceptions of Chemical Engineering Graduate Attributes at the University of Adelaide. Proc. Chemeca. Newcastle City Hall, New South Wales, Australia.

3. Belbin ${ }^{\circledR}$ Team Roles. Retrieved from http://www.belbin.com/rte.asp?id=1

4. $\quad$ Bodmer, C., Leu, A., Mira, L. \& Rutter, H. (2002). SPINE: Successful Practices in International Engineering Education: Engineers Shape our Future, IngCh.

5. Brown, J. S., Collins, A. and Duguid, P. (1989). Situated cognition and the culture of learning. Educational Researcher, 18(1), 32-42.

6. Choo, C, B. (2007). Activity-based approach to authentic learning in a vocational institute. Educational Media International, 44(3), 185-205.

7. Chun, M. (2010). Taking teaching to (performance) task: Linking pedagogical and assessment practices. Change, 42(2), 22-29.

8. Herrington, J., \& Oliver, R. (1991). Critical Characteristics of Situated Learning: Implications for the Instructional Design of Multimedia. Learning with technology, Withtechno, 253-262. University of Melbourne. Retrieved from http://www.ascilite.org.au/conferences/melbourne95/smtu/papers/herrington.pdf

9. Male, S. A., Bush, M. B. \& Chapman, E. S. (2010a). Perceptions of competency deficiencies in engineering graduates. Australasian Journal of Engineering Education, 16(1), 55-67. 
10. Male, S. A., Bush, M. B. \& Chapman, E. S. (2010b). Understanding generic engineering competencies. Proceedings of the 2010 Australian Association for Engineering Education Conference, Sydney.

11. Martin, R., Maytham, B., Case, J. \& Fraser, D. (2005). Engineering graduates' perceptions of how well they were prepared for work in industry. European Journal of Engineering Education, 30(2), 167-180.

12. McLellan, H. (1991). Virtual environments and situated learning. Multimedia Review, 2(3), 30-37.

13. McLellan, H. (1994). Situated learning: Continuing the conversation. Educational Technology, 34(10), 7-8.

14. Nair, C. S., Patel, A. \& Mertova, P. (2009). Re-engineering graduate skills - a case study. European Journal of Engineering Education, 34(2), 131-139.

15. Paris, S. G. \& Winograd, P. (1990). How Meta-cognition can promote academic learning and instruction, In B. F. Jones \& L. Idol (Eds.), Dimensions of Thinking and Cognitive Instruction. New Jersey, Lawrence Erlbaum Associates.

16. Perusich, K., Davis, B., Laware, G. \& Taylor, K. (2007). Assessing Teamwork for Accreditation: Understanding What Needs to be Known and Its Integration into Engineering and Technology Curricula. Proceedings from the $37^{\text {th }}$ ASEE/IEEE Frontiers in Education Conference, Session T3E. Milwaukee, WI.

17. Rychen, D. S. \& Salganik, L. H. (Eds.), (2003). Key competencies for a successful life and a well functioning society. Hogrefe \& Huber. Cambridge, MA.

18. Spinks, N., Silburn, N. \& Birchall, D. (2006). Educating Engineers for the 21st Century: The Industry View. The Royal Academy of Engineering, London.

19. Vygotsky, L. S. (1978). Mind in society: The development of higher psychological processes. Cambridge: Harvard University Press.

20. Wilhelm, J., Baker, T. \& Dube, J. (2001). Strategic Reading. Portsmouth, NH: Heinemann.

21. World Chemical Engineering Council (WCEC), (2004). How Does Chemical Engineering Education Meet The Requirements of Employment? Frankfurt.

22. Yu, H. (2008). Contextualize technical writing assessment to better prepare students for workplace writing: Student-centered assessment instruments. Journal of Writing and Communication, 38(3), 265-284.

23. Zaharim, A., Yusoff, Y. M., Omar, M. Z., Mohamed, A. \& Muhamad, N. (2008) Employers' Perceptions and Expectation toward Engineering Graduates: A Study Case. Proceedings of the 6th WSEAS International Conference on Engineering Education. Retrieved from http://www.wseas.us/reports/2008/venice/index.html 


\section{APPENDIX}

Student Engineering Multi-disciplinary Project Topics as examples of attempting solutions to real problems from their environment.

\section{Design of an Artificial Hand}

Green Buildings: Power Generation and Conservation using Hydrogen Fuel Cells

Integration of sustainable technologies in green buildings

Feasibility study of green technologies in energy-smart communities

Using Game Technology as a Learning Tool for Engineering Students

Healthy and Efficient Ventilation system design

Unmanned Aerial Vehicle to detect landmine locations in a given field

MEMS (Micro Electro Mechanical Systems) in Accelerometers 


\section{NOTES}

